\title{
An assessment on inclusion of private input dealers in the public extension services delivery system
}

\author{
Pachaiyappan K $K^{1}$, Rupasi Tiwari ${ }^{2}$, Mahesh Chander ${ }^{3}$ and Dwaipayan Bardhan ${ }^{4}$
}

Received: 21 June 2020 / Accepted: 03 July 2020 / Published online: 27 October 2020

(c) Indian Dairy Association (India) 2020

\begin{abstract}
The present study examined the amenability \& readiness of private input dealers in deliverance of dairy and other livestock extension services. "Q Methodology" was adopted in Kancheepuram and Villupuram districts of Tamil Nadu state with 26 identified input dealers, handling dairy and other livestock input items, during the year 2016. The attentiveness of the respondents towards their inclusion in the public extension services system', were estimated subjectively with the help of twenty five attitude statements which were moderated out of forty five statements. Principle Component Analysis (PCA) was used to categorize the statements under four identified discourses based on the obtained Eigen values. The four defined discourses viz., "Risks and opportunities in the endeavour", "Socio-economic empowerment in the undertaking", "Elements of collaboration in the endeavour" and "Possible refraining behaviour / escapism in the process"; in a nutshell had cued positive agreement of input
\end{abstract}

${ }^{1}$ SRRC of ICAR-CSWRI, Mannavanur, Kodaikanal, Tamil Nadu 624103

${ }^{2}$ ATIC, ICAR-Indian Veterinary Research Institute, Izatnagar, Uttar Pradesh - 243122

${ }^{3}$ Division of Extension Education, ICAR-Indian Veterinary Research Institute, Izatnagar, Uttar Pradesh - 243122

, ${ }^{4}$ Division of Livestock Economics \& Statistics, ICAR-Indian Veterinary Research Institute, Izatnagar, Uttar Pradesh - 243122

Pachaiyappan $\mathrm{K}(\square)$

SRRC of ICAR-CSWRI, Mannavanur, Kodaikanal, Tamil Nadu 624103

Email:pachaiyappank@gmail.com dealers to the statements supporting to their inclusion in public extension service stream.

Keywords: Extension Services Delivery, Private Input Dealers, Q Methodology, Principal Component Analysis

Input service providers in animal husbandry extend valuable services to the clients to maintain health and enhance productivity. Private input dealers, an integral part of livestock services, form a wide category as far as animal husbandry is concerned. The importance and utilization of experienced private sector players would strengthen the livestock services infrastructure, credit facilities, insurance, health care \& prophylaxis and identified areas of value addition and processing of livestock products including milk, meat, skin etc. Efforts to tap the potential of private input dealers are in process through some initiatives by the central and state authorities and one such effort is the "Diploma in Agricultural Extension Services for Input Dealers (DAESI)" program by National Institute of Agricultural Extension Management (MANAGE), Hyderabad. In this backdrop, the ability of private companies and dealers in rendering services to the livestock owners was felt to be thoroughly examined for utilizing their services in nation's agrarian cause. "Q Methodology" was followed and the attitudes of the respondents were estimated subjectively to assess the priorities $\&$ readiness of private input dealers in deliverance of livestock extension services. This subjectivity analysis was carried out in purposively selected Villupuram and Kancheepuram districts of Tamil Nadu involving 26 identified input dealers.. The past experience of the researcher in the districts as a Veterinary Services Execute in a reputed pharma company and subsequently as a Veterinary Officer with the state government; were pondered and this formed the basis to purposively select the districts, as rapport was felt as a critical factor to tap the respondents' subjective views on the research component. Only 26 input dealers were identified during the course of the research process due to limitations in identifying vivid input dealers in the study area.

Subjectivity is judgment based on individual personal impressions, feelings and opinions rather than external facts. This can be considered mind-dependent, because one is not using a fact, they are using their personal opinion (Amandaroseboyd, 2011). The increasing credibility of qualitative 
approaches for research has opened up new debates about methodology and rigor. The transition to a more subjective, reflexive approach to research brings benefits and with the loss of scientific rigor comes the gain of eliciting true meaning, by recreating the experiences of others through co-operative enquiry. Schultz (1994) argues that an openly subjective approach allows the researcher to be a real partner with informants, and to openly use his or her own experiences and reflections in order to uncover valuable meaning; adding value to the methodology. Q Methodology was adopted to subjectively analyse the input dealers' view on their inclusion in the mainstream extension services delivery system., as the method has been considered as a robust and relatively novel method in subjectively presenting the thoughts. It also is the method which has a combination of qualitative and quantitative entities (Gjalt de Graaf, 2007).

Q Methodology was developed by William Stephenson, an Englishman; Q methodology provides a foundation for the systematic study of subjectivity, a person's viewpoint, opinion, beliefs, attitude, and the like (Brown, 1993). In a Q methodological study, people are presented with a sample of statements about some topic, called the Q-set. Respondents, called the P-set, are asked to rank-order the statements from their individual point of view, according to some preference, judgment or feeling about them. By Q sorting, people give their subjective meaning to the statements, and by doing so reveal their subjective viewpoint. These individual rankings (or viewpoints) are then subject to factor/principal component analysis. By correlating people, $\mathrm{Q}$ factor analysis gives information about similarities \& differences in viewpoint on a particular subject and the factors resulting from $\mathrm{Q}$ analysis thus represent clusters of subjectivity that are operant (Smith, 2001). As per Van Excel and de Graff(2005), the means and process of Q method can be explained like "A person is presented with a set of statements about some topic, and is asked to rank-order them (usually from 'agree' to 'disagree'), referred to as ' $Q$ sorting.' The statements are matters of opinion only (not fact), and the fact that the $\mathrm{Q}$ sorter is ranking the statements from his or her own point of view is what brings subjectivity into the picture. The analytical process of Q method reduces the data based on principal components analysis (PCA) or factor analysis (FA). However, instead of correlating variables (as in regular PCA and FA), in Q the respondents are correlated in order to elucidate the relationships between them. The final results consist of a small number of sets of sorted statements, which are different from each other and summarize the perspectives existing among the

Table 1 Rotated component matrix

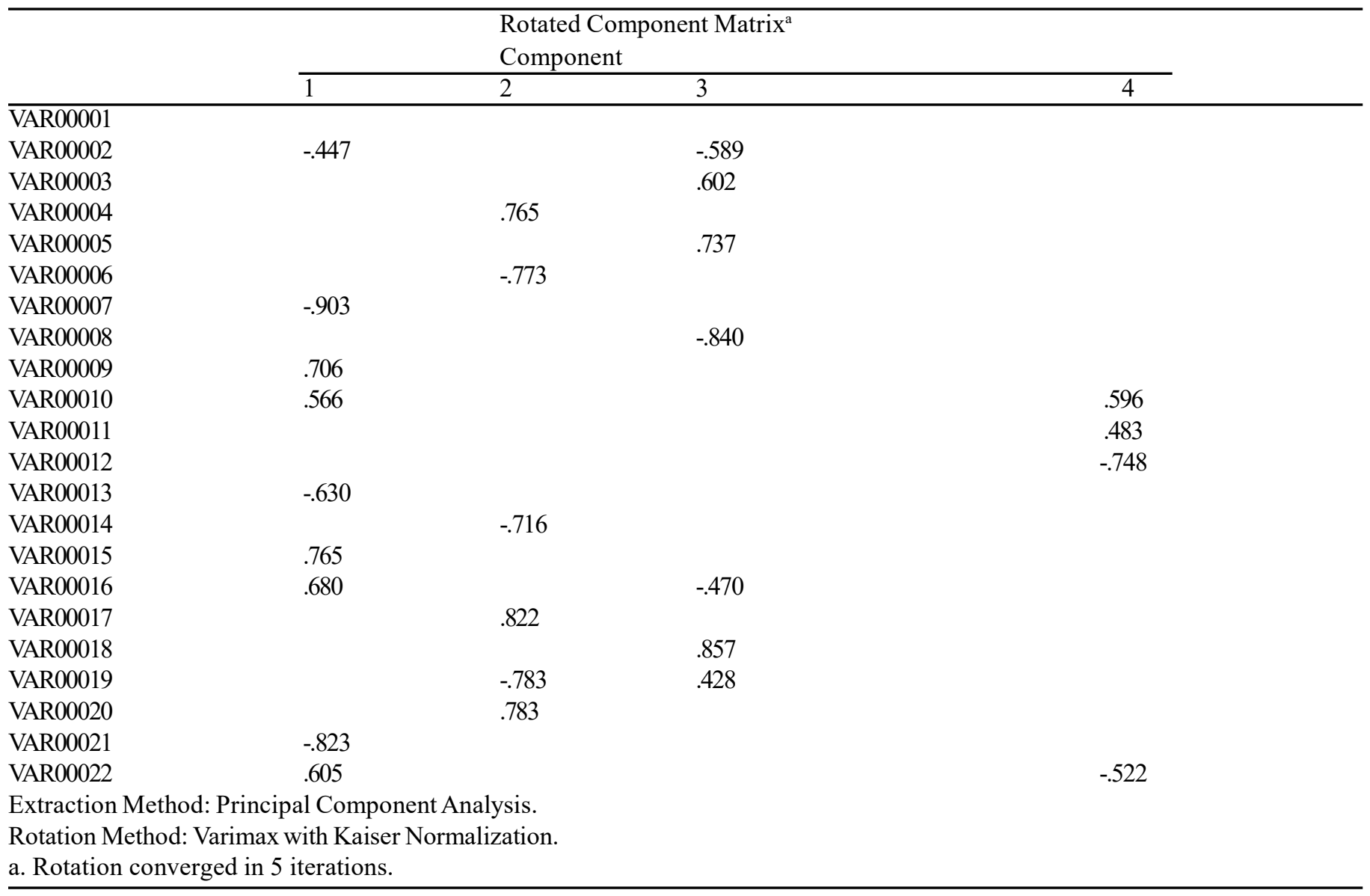


respondents (Zabola, 2014). The results of a Q methodological study can be used to describe a population of viewpoints and not, like in other method called R method; a population of people (Risdon et al. 2003).

The "Q" set for this study consisted of 25 statements which was moderated among 45 identified statements by the researcher in consultation with fellow scientists and input dealers in the field; who ultimately did not fall in the "P" set-respondents. The identified statements (Q Set) were numbered and presented along with the distribution of respondents ( $\mathrm{P}$ Set) with the frequencies up on their degrees of agreement (highly agree to highly disagree). The analysis of the $\mathrm{Q}$ sorts is purely technical, objective procedure - and is therefore sometimes referred to as the scientific base of Q. First, the correlation matrix of all Q sorts was calculated. This matrix represents the level of agreement/disagreement between the individual sorts, that is, the degree of similarity/dissimilarity in points of view between the individual Q sorters. The correlation matrix then was subjected to principal component analysis, with the objective to identify the number of natural groupings of $\mathrm{Q}$ sorts by virtue of being similar or dissimilar to one another, to examine how many basically different $\mathrm{Q}$ sorts are in evidence.

Principal component analysis (PCA) is a statistical procedure that uses an orthogonal transformation to convert a set of observations of possibly correlated variables into a set of values of linearly uncorrelated variables called principal components. The number of principal components is less than or equal to the number of original variables. PCA is mostly used as a tool in exploratory data analysis and for making predictive models. PCA can be done by Eigen value decomposition of a data covariance (or correlation) matrix or singular value decomposition of a data matrix, usually after mean centering (and normalizing or using Z-scores) the data matrix for each attribute.
The results of a PCA are discussed in terms of component scores, also called as factor scores and loadings i.e., the weight by which each standardized original variable should be multiplied to get the component score. The factors (out of 22 statements from 25) in each group deliver the most important information to reconstruct four discourses: four different views of private livestock input dealers about the inclusion of themselves in public extension system. Here, in each discourse description, first a label is presented; some relevant statements for the discourse are then presented, together with the idealized score of the four discourses. Then, a narrative of the discourse is presented. The composite sorts are used to interpret and describe the discourses and respondents' explanations on their ranking of statements have been discussed on the basis of interaction made with them. Discussion would have emphasis on the variable having a minimum significant score of 0.6 , as it has been fixed on analyzing the factor values across the table 1 .

The interpretation and conclusion in Q method is done by explanations based on the increased factor loadings and sign of the value obtained from the $\mathrm{Q}$ sorts, after computing Principal component analysis and has been presented in the table 2 . To sum up the analysis, statements having obtained high factor loadings (both + and - values) in all the discourses had to be presented and general views and insight of the respondents on the present topic of interest had to be analyzed in all possible dimensions. In the first factor discourse "Risks and opportunities in the endeavor, among the seven presented variables, statement about risky nature of the process' possessed the maximum factor score of -.903 followed by statement on procedural intricacies' and one on government policies', both had factor scores -.823 and 0.765 respectively with sign difference. The respondents' had a keen view and acceptance on the negative side that the inclusion venture may not go risky, in other words the input dealers did not have a concern over the risk

Table 2 Categorized variables (statements) and their Eigen scores

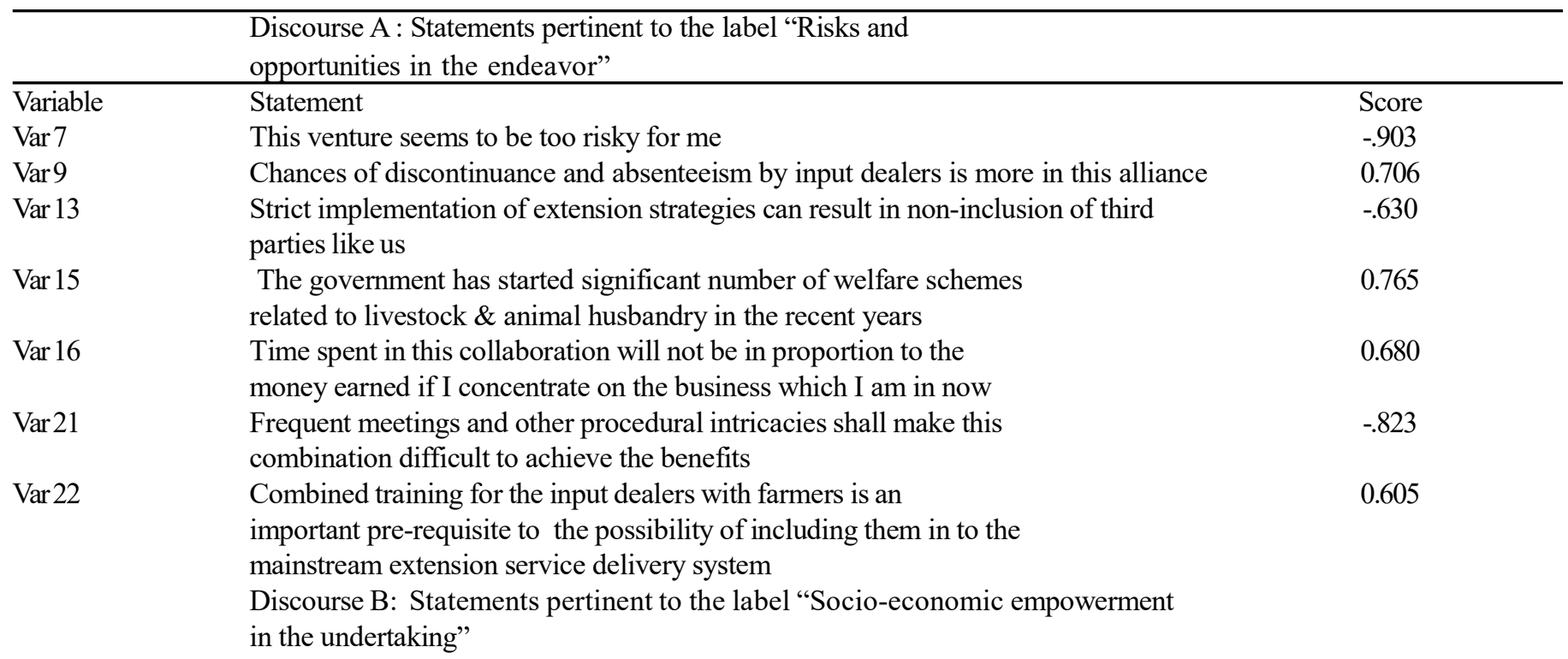




\begin{tabular}{|c|c|c|}
\hline Variable & Statement & Score \\
\hline Var 4 & $\begin{array}{l}\text { Input dealers can be utilized by the government for their efforts } \\
\text { leading to widespread technology transfer }\end{array}$ & 0.765 \\
\hline $\operatorname{Var} 6$ & $\begin{array}{l}\text { Surge of information and ease in attaining them is going to be very } \\
\text { useful for the needy farming community }\end{array}$ & -.773 \\
\hline Var 14 & Young and middle age entrepreneurs can make this collaboration effective & -.716 \\
\hline $\operatorname{Var} 17$ & Special status shall be provided to input dealers involved in public service & 0.822 \\
\hline Var 19 & Number of collaborative efforts should be minimal for effective functioning & -.783 \\
\hline $\operatorname{Var} 20$ & $\begin{array}{l}\text { Veterinarians often guide us in stock maintenance and market } \\
\text { orientation for more profitable business } \\
\text { Discourse C: Statements pertinent to the label "Elements of collaboration in the endeavor" }\end{array}$ & 0.783 \\
\hline Variable & Statement & Score \\
\hline Var2 & $\begin{array}{l}\text { Government - private input dealers' collaboration can be a fruitful } \\
\text { venture for people cause }\end{array}$ & -.589 \\
\hline Var 3 & Public's recognition is difficult to achieve in this mode of operation & 0.602 \\
\hline $\operatorname{Var} 5$ & Comfort zone in my business will be in stake if I get involved in this activity & 0.737 \\
\hline $\operatorname{Var} 8$ & $\begin{array}{l}\text { Information availability in this global era is easy and abundant not } \\
\text { only for farmers but for all }\end{array}$ & -.840 \\
\hline Var 18 & $\begin{array}{l}\text { The collaboration between government and private input dealers } \\
\text { shall be effective if it is incentive based } \\
\text { Discourse D: Statements pertinent to the label "Possible } \\
\text { refraining behavior / escapism in the process" }\end{array}$ & 0.857 \\
\hline Variable & Statement & Score \\
\hline Var 10 & $\begin{array}{l}\text { Service is not the primary motto for any businessman including } \\
\text { livestock input dealers like me }\end{array}$ & 0.596 \\
\hline Var 11 & $\begin{array}{l}\text { Line department officers may render deserving respect and regard } \\
\text { to input dealers in this collaboration }\end{array}$ & 0.483 \\
\hline $\operatorname{Var} 12$ & $\begin{array}{l}\text { Manpower lacuna is the important factor for the prevailing } \\
\text { situations in extension services delivery }\end{array}$ & -.748 \\
\hline $\operatorname{Var} 22$ & $\begin{array}{l}\text { Combined training for the input dealers with farmers is an important } \\
\text { pre-requisite to this initiative }\end{array}$ & -.522 \\
\hline
\end{tabular}

involved in the inclusion process. The degree of disagreement to procedural intricacies and agreement on the variable, innumerable initiatives by the governments carries impressive factor load.

The second factor discourse "Socio-economic empowerment in the undertaking", among the six presented variables in the second group, statement about special status to the input dealers possesses the maximum factor score of 0.822 which implies that the input dealers if collaborated, should be given special status by means of recognizing them with honours and awards, a very positive step in the direction. Statement on incentive-based collaboration' topped the group with an impressive factor score 0.857 in the third factor discourse "Elements of collaboration in the endeavor" referring the private input dealers', depicting the importance of the financial element in the inclusion process. The fourth factor discourse "Possible refraining behaviour / escapism in the process" had highlighted the statement on manpower paucity and prevailing situations in extension services delivery' with factor loading -.748 . In a nutshell the statements and the discourses categorized and analyzed in the study cues on positive agreement of input dealers supporting to their inclusion in public extension service stream which can be pondered up on by the planners and policy makers in implementing the theme on pilot basis and furtherance to its augmentation.

\section{Conclusions}

Role of extension personnel is crucial in fostering collaboration and networking between and among different agencies so as to facilitate farming situations to stand at par with the market-driven economy (Ponnusamy and Pachaiyappan, 2018). Networking is all about involvement of multiple partners with same objective, and this reduces the efforts in scrambling extension services to the needy. Of late, the central and state governments have started numerous special schemes and efforts in empowering animal husbandry farmers and these schemes need multiple partners in the value chain for an effectual and speedy reach. Private input dealers, particularly the shop owners who directly deal with the livestock farmers in terms of OTC (over the counter sales) can very-well be a partner in outreaching the government's initiative. The research findings of this study also suggest the integration of input dealers in the value chain development process which 
can also be mediated through DAESI benefactors and other noted dealers on trial basis. Social recognition and incentive-based collaboration of the governments and input dealers, the concepts emerged from subjectivity analysis points confirmed the input dealers' agreement in the inclusion process; which might entice valid consideration by the implementing authorities thereby augmenting win-win situation for all the stake-holders in livestock services delivery system.

\section{Acknowledgements}

This article is from a part of $\mathrm{PhD}$ research by the first author. The authors would like to thank Director and Joint Directors of ICARIndian Veterinary Research Institute, Izatnagar for having provided permission and infrastructural/logistical facilities to successfully carryout the research work.

\section{References}

Amandaroseboyd (2011) Social Research: Objectivity vs. Subjectivity Blog. Available at https://amandaroseboyd.wordpress.com/2011/10/ 17/social-research-objectivity-vs-subjectivity/

Brown S R (1993) A Primer on Q Methodology. Operant subjectivity 16: 91-138

Gjalt de Graaf (2007) Veterinary Students' Views on Animal Patients and Human Clients, Using Q-Methodology. J Vet Med Educ 34: 127-138
Ponnusamy K, Pachaiyappan K (2018) Strengthening extension research in animal husbandry: review of issues and strategies. Indian J Anim Sci 88: 137-143

Risdon A, Eccleston C, Crombez G, McCracken L (2003) How can we learn to live with pain? AQ-methodological analysis of the diverse understandings of acceptance of chronic pain. Social Sci Med 56: 375-86

Schutz S E (1994) Exploring the benefits of a subjective approach in qualitative nursing research. J Adv Nursing 20: 412-417

Smith N W (2001) Current systems in psychology: history, theory, research, and applications. London: Wadsworth.

Van Exel N J, Gjalt de Graaf (2005) Q methodology: A sneak preview. [available from www.jobvanexel.nl]

Zabala A (2014) Q method: A package to explore human perspectives using Q methodology. The R J 6: 163-173 